\title{
STIMULATION OF DUODENAL CHOLECYSTOKININ RELEASE BY FATTY ACID OR TRYPSIN INHIBITOR IS MARKEDLY INHIBITED BY LUMINAL WASHING
}

\author{
Yasuhisa Sakamura, Shuji Kanayama, Yasuhisa Shinomura and Seitchiro Tarui \\ Second Department of Internal Medicine, Osaka University Medical School, Osaka 553, Japan
}

\begin{abstract}
To investigate the influence of intestinal fluid containing bile, pancreatic juice and intestinal secretions on the regulation of cholecystokinin (CCK) release, arterial perfusion of bombesin or intraduodenal infusion of trypsin inhibitor or fatty acid was performed in vascularly perfused rat duodenum. Bombesin and gabexate mesilate, a synthetic trypsin inhibitor, caused a prompt and transient CCK release. In contrast, sodium oleate caused a sustained CCK release. Removal of intestinal fluid by luminal washing significantly inhibited the CCK release by sodium oleate or by gabexate, but did not affect the CCK release by bombesin. Intraduodenal infusion of elaidic acid, a stereoisomer of oleic acid, did not stimulate CCK secretion. The results indicate that CCK secretion stimulated by fatty acid or by trypsin inhibitor is dependent on the intestinal fluid, but CCK secretion stimulated by bombesin is independent of the intestinal fluid. It is also indicated that stereoisomerism of fatty acid molecule is closely related to CCK-releasing activity.
\end{abstract}

Cholecystokinin (CCK) is most abundantly found in the proximal small intestine, and it stimulates gallbladder contraction and pancreatic enzyme secretion. CCK is secreted into the circulation after ingestion of nutrients. Protein and fatty acid are two major dietary factors that stimulate CCK secretion. Bombesin, a neuropeptide initially isolated from amphibian skin, also potently stimulates CCK secretion (5). Bombesin and its mammalian counterpart, gastrin-releasing peptide (GRP), stimulate both endocrine and exocrine secretions of the stomach and pancreas $(1,22)$. Bombesin and GRP have the identical amino acid sequence at the Cterminal 7 residues, which is a biologically active portion of each peptide; thus bombesin and GRP are identical in their biological actions and are similar in potency (19). Immunoreactivity for bombesin or GRP in rats is localized exclusively in nerve fibers throughout the gastrointestinal tract (2).

CCK secretion stimulated by dietary protein in rats is under negative feedback regulation by pancreatic secretion (7). In this feedback regulation, active proteases in the intestinal lumen inhibit CCK secretion; inactivation of intestinal proteases, binding of proteases to substrates, or trypsin inhibitor results in stimulation of CCK secretion $(4,16)$. It has been demonstrated that the ability of the protein to stimulate CCK secretion is attributable to its ability to serve as substrate for trypsin (15). Intestinal fluid containing bile, pancreatic juice, and intestinal secretions has been demonstrated to play an important role in CCK secretion stimulated by proteins or trypsin inhibitor $(8,20)$. However, little is known whether or not intestinal fluid influences CCK secretion stimulated by fat or bombesin.

In the present study, the influence of intestinal fluid on CCK secretion stimulated by arterial perfusion of bombesin, intraduodenal infusion of trypsin inhibitor or fatty acid was investigated in vascularly perfused rat duodenum. In addition, the relation of conformation of fatty acid molecule to CCK-releasing activity was examined using a stereoisomer of oleic acid. 


\section{MATERIALS AND METHODS}

\section{Surgical Preparation}

Male Wistar rats weighing 250-300 g, after an overnight fast, were anesthetized with sodium pentobarbital ( $40 \mathrm{mg} / \mathrm{kg}$ i.p.). Vascularly perfused rat duodenum with attached pancreas was prepared by a modification of the method of Kanno et al. (13). An inlet cannula was inserted into the duodenum via a small incision of the stomach and an outlet cannula was inserted from the distal end of the duodenum. Then, the duodenum was ligated at pyloric ring and at anal end and the outlet cannula was closed to prevent leakage of intestinal fluid. Vessels flowing to the stomach, spleen and kidney were ligated. The common bile duct was also ligated. A metal cannula $(0.65 \mathrm{~mm}$ O.D.) was inserted into the aorta and perfusion was started from both the superior mesenteric artery and coeliac artery. Portal effluent was collected continuously from a polyethylene tube ( $2.3 \mathrm{~mm}$ O.D.) introduced into the portal vein. The perfusion was done with modified Krebs-Henseleit bicarbonate (modified KHB) solution, whose composition was as follows (final concentration, $\mathrm{mM}$ ): $\mathrm{NaCl}, 131 ; \mathrm{KCl}, 5.6$; $\mathrm{CaCl}_{2}, 2.5 ; \mathrm{MgCl}_{2}, 1.0 ; \mathrm{NaHCO}_{3}, 25$; glucose, 5.0; HEPES, 1.0. To prevent edema of the preparation and adherence of peptides to tubes, $5 \%$ dextran (M.W. 60,000-90,000, Sigma, St. Louis, MO) and $0.2 \%$ gelatin (Wako Pure Chemical, Osaka) were added to the perfusate, which was continuously gassed with $95 \% \mathrm{O}_{2}-5 \% \mathrm{CO}_{2}$ and kept at $\mathrm{pH} 7.4$. The whole preparation was placed in a bath filled with modified $\mathrm{KHB}$ solution at $37^{\circ} \mathrm{C}$.

\section{Experimental Procedures}

The perfusion was done at a flow rate of $2 \mathrm{ml} / \mathrm{min}$, and the portal effluent was collected as $2.5 \mathrm{~min}$ fractions into chilled plastic tubes and frozen at $-20^{\circ} \mathrm{C}$ until use. When luminal washing was performed, the outlet cannula was opened and the intestinal fluid was removed by introducing $20 \mathrm{ml}$ of modified KHB solution and then $5 \mathrm{ml}$ of air into the duodenal lumen through the inlet cannula and the intestinal washes were introduced out of the duodenum to the outlet cannula. The outlet cannula was closed at the end of the luminal washing. After $5 \mathrm{~min}$ of basal perfusion period, instillation of intraduodenal stimulants or perfusion with an intraarterial stimulant was performed. Perfusion with $10^{-6} \mathrm{M}$ bombesin (Peptide Institute, Osaka) was performed for $10 \mathrm{~min}$ followed by $15 \mathrm{~min}$ of observation period. Gabexate mesilate, ethyl-4-(6guanidinohexanoyloxy)benzoate methasulfonate (Ono Pharmaceutical, Osaka), a synthetic trypsin inhibitor, was dissolved in modified KHB solution to a concentration of $20 \mathrm{mg} / \mathrm{ml}$. Sodium oleate (Wako Pure Chemical, Osaka) was used as $0.125 \mathrm{M}$ aqueous solution. Elaidic acid, trans-9-octadecenoic acid (Nacalai Tesque, Kyoto), was prepared as sodium salt in $0.125 \mathrm{M}$ aqueous solution and adjusted with $\mathrm{NaOH}$ to the same $\mathrm{pH}$ as the sodium oleate solution ( $\mathrm{pH}$ 10.3). Two $\mathrm{ml}$ of the solution containing $20 \mathrm{mg} / \mathrm{ml}$ gabexate, $0.125 \mathrm{M}$ sodium oleate, or $0.125 \mathrm{M}$ elaidic acid were infused into the duodenal lumen and retained there for $25 \mathrm{~min}$.

\section{Gel Chromatography}

Fractions of portal effluent containing the highest concentration of CCK under stimulation with gabexate without luminal washing were applied to a Sephadex G-50 superfine column $(1 \times 95 \mathrm{~cm})$. Chromatographic analyses were done as described previously (12).

\section{Radioimmunoassay}

CCK concentrations in portal effluent and column effluent were measured by a minor modification of the method described previously (12). Separation of free hormones from antibody-bound hormones was achieved by polyethylene glycol. CCK-specific antiserum (OAL 656) cross-reacted with sulfated gastrin in $0.18 \%$. The antiserum did not cross-react with structurally unrelated gastrointestinal peptides such as secretin and bombesin.

\section{Calculation and Statistical Analysis}

The CCK amount was integrated by summating the increase in CCK output above the basal during 25 min after the start of stimulation. All values were expressed as means \pm SE. Statistical analysis was made using Student's $t$-test. Differences between any two values were considered significant if $P$ value was lower than 0.05 .

\section{RESULTS}

Effect of Luminal Washing on the Basal CCK Secretion

Mean CCK level in portal effluent during 5 min of 


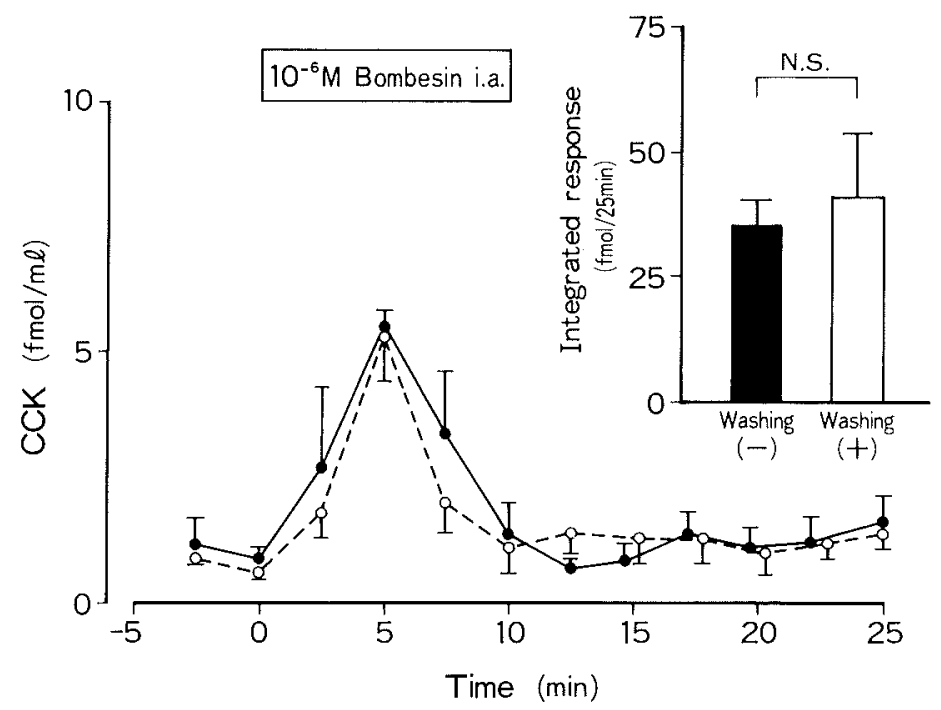

Fig. 1 Effect of arterial infusion of $10^{-6} \mathrm{M}$ bombesin on CCK concentration in portal effluent from vascularly perfused rat duodenum without $(\bullet)$ and with $(0)$ luminal washing. The insert shows the CCK value integrated during 25 min after the start of stimulation without ( $(\mathbf{)}$ and with ( $\square$ ) luminal washing. Intestinal fluid was removed by luminal washing with $20 \mathrm{ml}$ of modified KHB solution and $5 \mathrm{ml}$ of air immediately before the start of basal perfusion. Values are means \pm SE from 5 (without washing) or 4 (with washing) rats. N.S.: not significant

basal perfusion was $1.0 \pm 0.1 \mathrm{fmol} / \mathrm{ml}$ in 23 experiments without luminal washing, and $1.0 \pm 0.1$ $\mathrm{fmol} / \mathrm{ml}$ in 15 experiments with luminal washing which was performed just before the start of basal perfusion. There was no significant difference between the basal CCK levels without and with luminal washing.

\section{CCK Release by Arterial Perfusion with Bombesin}

Arterial perfusion with $10^{-6} \mathrm{M}$ bombesin without luminal washing caused a transient elevation of CCK levels in portal effluent (Fig. 1). CCK levels in the portal effluent rose from the basal level of $1.0 \pm 0.2 \mathrm{fmol} / \mathrm{ml}$ to a peak level of $5.5 \pm 0.3 \mathrm{fmol} / \mathrm{ml}$ at $5 \mathrm{~min}$ and returned to the basal level at $10 \mathrm{~min}$ after the start of bombesin perfusion. The integrated CCK value in response to bombesin without luminal washing was $35.0 \pm 5.2 \mathrm{fmol} / 25 \mathrm{~min}$.

Luminal washing did not affect CCK secretion stimulated by $10^{-6} \mathrm{M}$ bombesin (Fig. 1), the integrated CCK value with luminal washing being $40.9 \pm 12.7 \mathrm{fmol} / 25 \mathrm{~min}$.

\section{CCK Release by Intraduodenal Infusion of a Trypsin Inhibitor}

Intraduodenal infusion of gabexate $(40 \mathrm{mg})$ with- out luminal washing also caused a transient elevation of portal CCK levels (Fig. 2). CCK levels in portal effluent rose to $21.5 \pm 2.1 \mathrm{fmol} / \mathrm{ml}$ at $5 \mathrm{~min}$ and returned to the basal level at $12.5 \mathrm{~min}$ after the start of gabexate administration. The integrated CCK value in response to gabexate without luminal washing was $179.5 \pm 21.6 \mathrm{fmol} / 25 \mathrm{~min}$.

Luminal washing inhibited CCK secretion stimulated by gabexate (Fig. 2). The integrated CCK value with luminal washing was $69.0 \pm 14.6 \mathrm{fmol} /$ 25 min, which was significantly lower than that without luminal washing.

\section{CCK Release by Intraduodenal Infusion of Fatty Acid}

Unlike stimulation with bombesin or trypsin inhibitor, intraduodenal infusion of sodium oleate $(0.25 \mathrm{mmol})$ without luminal washing caused a sustained elevation of portal CCK levels during $25 \mathrm{~min}$ (Fig. 3). The highest CCK level in portal effluent and the integrated CCK value in response to sodium oleate without luminal washing were $8.3 \pm$ $0.9 \mathrm{fmol} / \mathrm{ml}$ and $218.1 \pm 26.4 \mathrm{fmol} / 25 \mathrm{~min}$, respectively.

Luminal washing inhibited CCK secretion stimulated by sodium oleate (Fig. 3). The integrated CCK value in response to sodium oleate with lumi- 


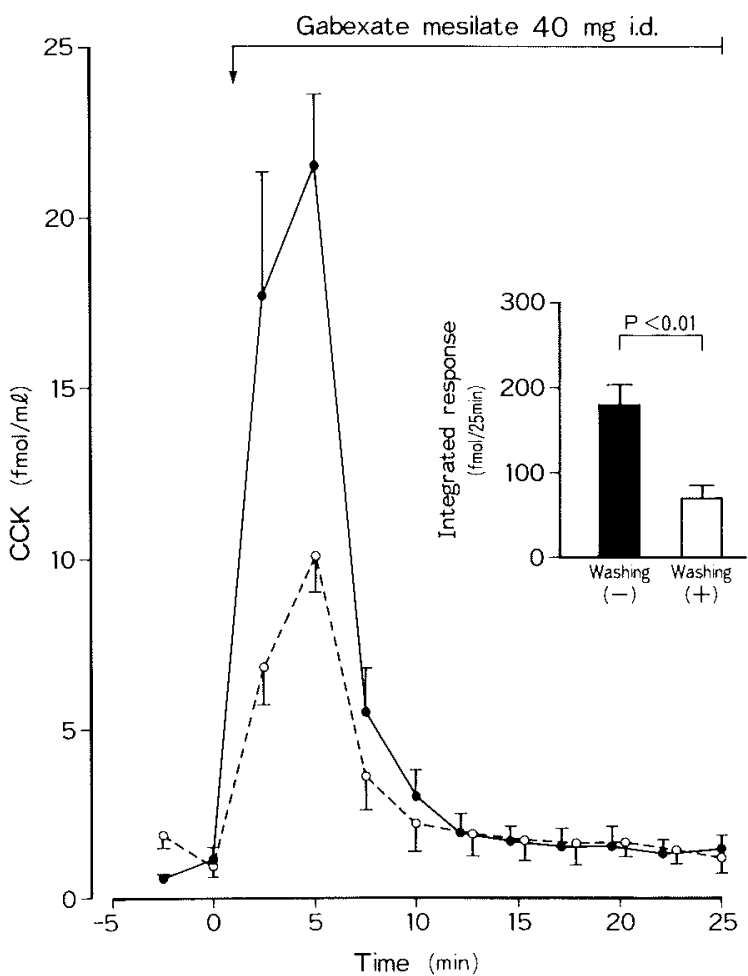

Fig. 2 Effect of luminal infusion of gabexate $(40 \mathrm{mg})$ on CCK concentration in portal effluent from vascularly perfused rat duodenum without (•) and with (o) luminal washing. The insert shows the CCK value integrated during 25 min after the start of stimulation without (a) and with (口) luminal washing. Values are means \pm SE from 8 (without washing) or 6 (with washing) rats.

nal washing was $61.8 \pm 11.7 \mathrm{fmol} / 25 \mathrm{~min}$, which was significantly lower than the value without luminal washing.

Intraduodenal infusion of elaidic acid $(0.25$ mmol) without luminal washing, did not significantly increase CCK levels in portal effluent (Fig. $3)$.

\section{Chromatographic Analyses of the Released CCK}

Gel chromatography of portal effluent containing the highest concentration of CCK under stimulation of gabexate revealed two major peaks: one was eluted at a position similar to CCK-8 and the other between CCK-33 and CCK-8 (Fig. 4).

\section{DISCUSSION}

Using the vascularly perfused rat duodenum, it is possible to investigate the CCK secretion inde-

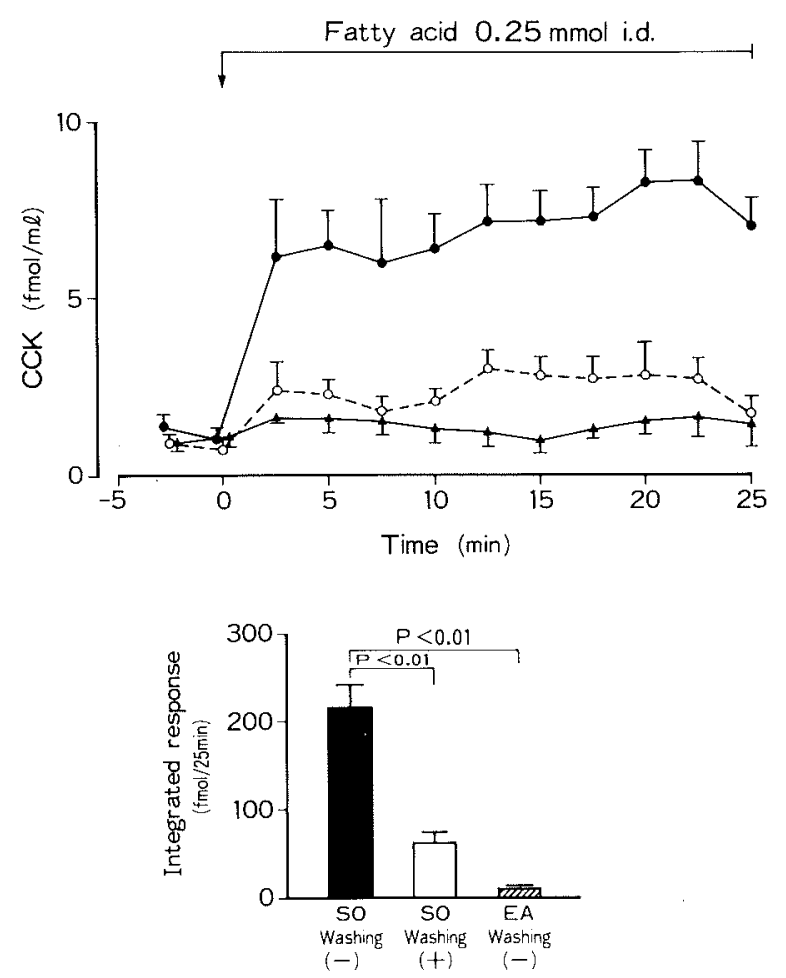

Fig. 3 Upper panel: effects of luminal infusion of fatty acid on CCK concentration in portal effluent from vascularly perfused rat duodenum; stimulation by sodium oleate $(0.25 \mathrm{mmol})$ without (e) and with (o) luminal washing, and stimulation by elaidic acid $(0.25 \mathrm{mmol})$ without luminal washing (৯). Lower panel: CCK values integrated during 25 min after the start of stimulation; stimulation by sodium oleate (SO) without ( $\mathbf{m}$ ) and with (D) luminal washing, and stimulation by elaidic acid (EA) without luminal washing ( Values are means $\pm \mathrm{SE}$ from 5 rats.

pendently from extrinsic neural or hormonal regulation, and without elimination of CCK by the liver. In the present study, luminal washing inhibited CCK secretion stimulated not only by gabexate but also by sodium oleate, but did not affect CCK secretion stimulated by bombesin. It is unlikely that the inhibition of CCK secretion after luminal washing is due to a mechanical injury, because neither CCK release by bombesin nor basal CCK level immediately after luminal washing was affected by luminal washing. The inhibition of CCK secretion after luminal washing indicates that intestinal fluid plays an important role in CCK release by gabexate or by sodium oleate. Luminal washing partially inhibited CCK secretion stimulated by gabexate or by sodium oleate. The procedure of luminal washing in 


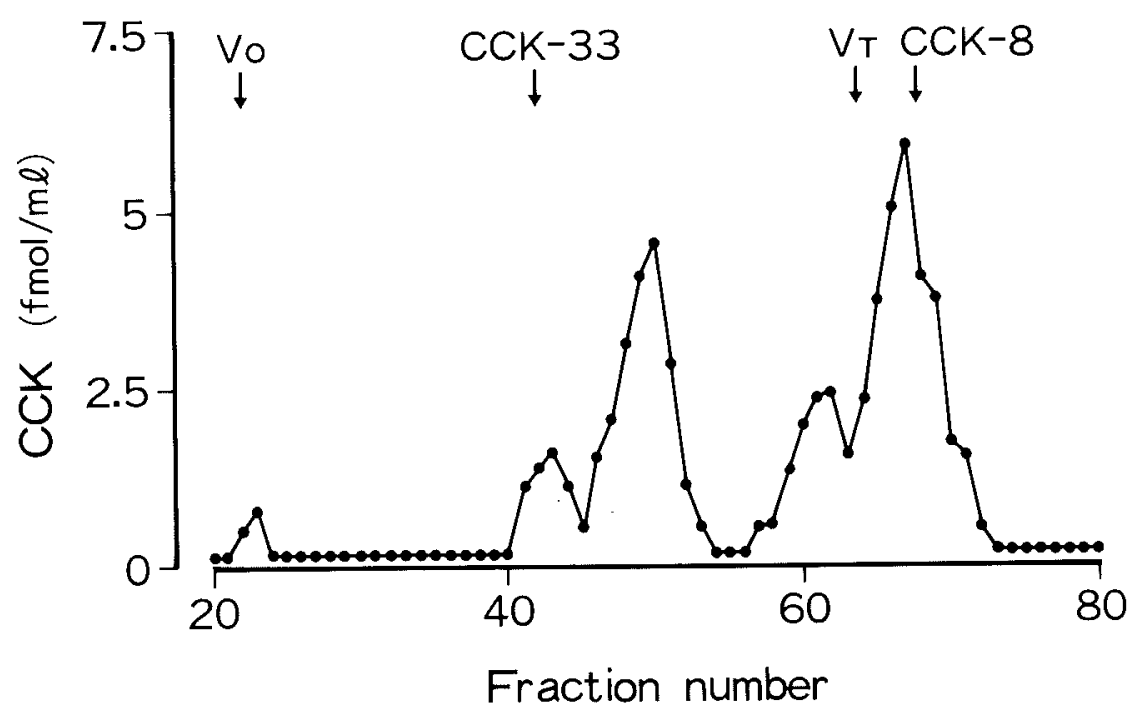

Fig. 4 Elution profile of portal effluent under gabexate stimulation. Sephadex G-50 superfine column chromatography. Fractions of portal effluent containing the highest concentration of CCK under gabexate stimulation without luminal washing were applied. A representative profile is shown. The column had previously been calibrated with $\mathrm{Na}^{125} \mathrm{I}\left(\mathrm{V}_{\mathrm{T}}\right)$, albumin (Vo), CCK-33, and CCK-8.

the present study may not have removed the intestinal fluid completely from the duodenal lumen or from the crypts of the duodenal mucosa. The residual CCK secretion stimulated by gabexate or by sodium oleate after luminal washing may be due to the intestinal fluid remained in the duodenum.

It has recently been proposed that CCK release by protein or trypsin inhibitor is regulated by two kinds of CCK-releasing factors: a trypsin-sensitive, heat-stable CCK-releasing peptide from intestinal secretions $(17,21)$, and a monitor peptide isolated from pancreatic juice $(9,10)$. When dietary protein or trypsin inhibitor suppresses the activity of intestinal proteases by binding to them, the CCK-releasing factors, protected from inactivation by these proteases, result in stimulation of CCK secretion. A possible explanation for the role of intestinal fluid in CCK release by trypsin inhibitor is that the luminal washing removes these CCK-releasing factors in intestinal fluid and, as a result, reduces CCK secretion by the CCK-releasing factors. Therefore, the present study may provide a supportive evidence for the hypothesis that protein or trypsin inhibitor suppresses the inactivation of CCKreleasing factors caused by intestinal proteases, which in turn stimulates CCK secretion.

Protein and fatty acid are known as two major dietary factors in CCK release. However, little is known about the role of intestinal fluid in CCK release by fatty acid. In the present study, luminal washing also inhibited CCK release by sodium oleate. The result indicates that intestinal fluid plays an important role in CCK release by fatty acid, and suggests that stimulation of CCK release by fatty acid is not a direct action on CCK-containing cells, but a cooperative action of fatty acid with intestinal fluid. It remains to be known whether the inhibition by luminal washing of the CCK secretion stimulated by fatty acid could be explained by a similar mechanism, i.e. the negative freedback regulation mediated by intestinal proteases, since fatty acid itself is not a substrate for proteases. Further studies are necessary to understand the precise mechanism of duodenal CCK release by trypsin inhibitor or fatty acid.

It has been demonstrated that the CCK-releasing activity of fatty acid is related to its chemical structure, i.e. carbon chain length and carboxy group of the molecule $(18,23)$. In the present study, elaidic acid did not stimulate CCK secretion. Elaidic acid is the trans isomer of oleic acid having the same number of carbon and carboxy group, but is very rare among naturally occurring fatty acids. The lack of CCK-releasing activity of elaidic acid suggests that the molecular conformation of fatty acid is also involved in CCK release.

Unlike intraduodenal infusion of trypsin inhibitor or fatty acid, arterial perfusion of bombesin 
stimulated CCK secretion independently of the intestinal fluid. Bombesin-like immunoreactivity is localized exclusively in nerve fibers throughout the gastrointestinal tract in rats (2). Bombesin may stimulate intestinal CCK secretion as a neural factor through a mechanism different from that of intraluminal trypsin inhibitor or fatty acid.

Chromatography revealed that CCK released from the perfused rat duodenum contained two major components: a CCK-8 like form and an intermediate form between CCK-33 and CCK-8. The latter form is compatible with CCK-22 reported in the rat intestine (3). The CCK components reported by Fölsch et al. in rat portal plasma are consistent with those in our present study (4). In contrast, the CCK-22 like form, but not CCK-8 like form, is predominant in the rat circulating blood $(12,14)$. The difference in molecular forms of CCK between circulating blood and portal effluent can be explained by a preferential elimination of CCK-8 by the liver $(6,11)$.

Received 3 October 1990; accepted 10 December 1990

\section{REFERENCES}

1. Chowdhury P., Ami M. and Rayford P. L. (1986) Effect of cadmium and bombesin on exocrine pancreatic secretions and plasma levels of gastrin and cholecystokinin (CCK) in rats. Ann. Clin. Lab. Sci. 16, 479-487

2. Dockray G. J., Vaillant C. and Walsh J. H. (1979) The neuronal origin of bombesin-like immunoreactivity in the rat gastrointestinal tract. Neuroscience 4, 1561-1568

3. Eng J., Du B.-H., Pan Y.-C. E., Chang M., Hulmes J. D. and Yalow R. S. (1984) Purification and sequencing of a rat intestinal 22 amino acid C-terminal CCK fragment. Peptides 5, 1203-1206

4. Fölsch U. R., Cantor P., Wilms H. M., Schafmayer A., Becker H. D. and Creutzfeldt W. (1987) Role of cholecystokinin in the negative feedback control of pancreatic enzyme secretion in conscious rats. Gastroenterology 92 , 449-458

5. Ghatei M. A., Jung R. T., Stevenson J. C., Hillyard C. J., Adrian T. E., Lee Y. C., Christofides N. D., Sarson D. L., Mashiter K., Macintyre I. and Bloom S. R. (1982) Bombesin: Action on gut hormones and calcium in man. $J$. Clin. Endocrinol. Metab. 54, 980-985

6. Gores G. J., LaR usso N. F. and Miller L. J. (1986) Hepatic processing of cholecystokinin peptides. I. Structural specificity and mechanism of hepatic extraction. Amer: $J$. Plysiol. 250, G344-G349

7. GReEN G. M. and Lyman R. L. (1972) Feedback regulation of pancreatic enzyme secretion as a mechanism for trypsin inhibitor-induced hypersecretion in rats. Proc. Soc. Exp. Biol. Med. 140, 6-12
8. Green G. M. and Nasser E. S. (1980) Importance of bile in regulation of intraluminal proteolytic enzyme activities in the rat. Gastroenterology 79, 695-702

9. Imai K., Fukuoka S., Fushiki T., Tsujikawa M., Hirose M., Tsunasawa S. and SaKiYama F. (1987) Purification and sequencing of a trypsin-sensitive cholecystokinin-releasing peptide from rat pancreatic juice. J. Biol. Chem. 262, 89568959

10. Iwal K., Fushiki T. and Fukuoka S. (1988) Pancreatic enzyme secretion mediated by novel peptide: Monitor peptide hypothesis. Pancreas 3, 720-728

11. Kanayama S., Himeno S., Kurokawa M., Shinomura Y., Kuroshima T., Okuno M., Tsuji K., Higashimoto Y., IKei N., Hashimura E., Tateishi K., Hamaoka T. and Tarui S. (1985) Marked prolongation in disappearance half-time of plasma cholecystokinin-octapeptide in patients with hepatic cirrhosis. Amer: J. Gastroenterol. 80, 557-560

12. Kanayama S., Himeno S., Yamasaki Y., Shinomura Y., KiTANI T. and TARUi S. (1987) Effect of synthetic trypsin inhibitor on plasma immunoreactive cholecystokinin in rats. Gastroenterol. Jap. 22, 211-217

13. Kanno T., Suga T. and Yamamoto M. (1976) Effects of oxygen supply on electrical and secretory responses of humorally stimulated acinar cells in isolated rat pancreas. Jap. J. Physiol. 26, 101-115

14. Lidple R. A., Goldfine I. D. and Williams J. A. (1984) Bioassay of plasma cholecystokinin in rats: Effects of food, trypsin inhibitor, and alcohol. Gastroenterology 87, 542-549

15. Liddle R. A., Green G. M., Conrad C. K. and Williams J. A. (1986) Proteins but not amino acids, carbohydrates, or fats stimulate cholecystokinin secretion in the rat. Amer. $J$. Physiol. 251, G243-G248

16. Louie D. S., May D., Miller P. and Owyang C. (1986) Cholecystokinin mediates feedback regulation of pancreatic enzyme secretion in rats. Amer. J. Physiol. 250, G252G259

17. Lu L., Louie D. and OwYANG C. (1989) A cholecystokinin releasing peptide mediates feedback regulation of pancreatic secretion. Amer: J. Physiol. 256, G430-G435

18. Meyer J. H. and Jones R. S. (1974) Canine pancreatic responses to intestinally perfused fat and products of fat digestion. Amer. J. Physiol. 226, 1178-1187

19. McDonald T. J., Ghatei M. A., Bloom S. R., Track N. S., Radziuk J., Dupre J. and Mutt V. (1981) A qualitative comparison of canine plasma gastroenteropancreatic hormone responses to bombesin and the porcine gastrinreleasing peptide (GRP). Regul. Peptides 2, 293-304

20. Miyasaka K. and Green G. M. (1984) Effect of partial exclusion of pancreatic juice on rat basal pancreatic secretion. Gastroenterology 86, 114-119

21. Miyasaka K., Guan D., Liddie R. A. and Green G. M. (1989) Feedback regulation by trypsin: evidence for intraluminal CCK-releasing peptide. Amer, J. Physiol. 257, G175-G181

22. Miyata M., Rayford P. L. and Thompson J. C. (1980) Hormonal (gastrin, secretin, cholecystokinin) and secretory effects of bombesin and duodenal acidification in dogs. Surgery 87, 209-215

23. Olsen O., Ainsworth M., Schaffalitzky de Muckadell O. B. and CANTOR P. (1989) Effects of oleic acid and oleyl alcohol on cholecystokinin and secretin in plasma and pancreatobiliary secretion. Scand. J. Gastroenterol. 24, 529-532 